\title{
OVERLAND FLOW ANALYSIS USING TIME SERIES OF SUAS-DERIVED ELEVATION MODELS
}

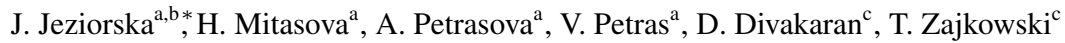 \\ ${ }^{a}$ Department of Marine, Earth, and Atmospheric Sciences, North Carolina State University - (jajezior, hmitaso, akratoc, vpetras @ ncsu.edu) \\ ${ }^{\mathrm{b}}$ Department of Geoinformatics and Cartography, University of Wroclaw \\ ${ }^{c}$ NextGen Air Transportation (NGAT), Institute for Transportation Research and Education, \\ North Carolina State University - (ddivaka2, tjzajkow @ncsu.edu)
}

KEY WORDS: UAS, UAV, sUAS, lidar, digital elevation model, overland flow modeling, path sampling

\begin{abstract}
:
With the advent of the innovative techniques for generating high temporal and spatial resolution terrain models from Unmanned Aerial Systems (UAS) imagery, it has become possible to precisely map overland flow patterns. Furthermore, the process has become more affordable and efficient through the coupling of small UAS (sUAS) that are easily deployed with Structure from Motion (SfM) algorithms that can efficiently derive 3D data from RGB imagery captured with consumer grade cameras. We propose applying the robust overland flow algorithm based on the path sampling technique for mapping flow paths in the arable land on a small test site in Raleigh, North Carolina. By comparing a time series of five flights in 2015 with the results of a simulation based on the most recent lidar derived DEM (2013), we show that the sUAS based data is suitable for overland flow predictions and has several advantages over the lidar data. The sUAS based data captures preferential flow along tillage and more accurately represents gullies. Furthermore the simulated water flow patterns over the sUAS based terrain models are consistent throughout the year. When terrain models are reconstructed only from sUAS captured RGB imagery, however, water flow modeling is only appropriate in areas with sparse or no vegetation cover.
\end{abstract}

\section{INTRODUCTION}

Mapping hydrological pathways by which water moves over and through the Earth surface is essential for explaining hydrological, geomorphological, ecological and geochemical phenomena (Hyväluoma et al., 2013; Bevington et al., 2016). Precise and detailed representations of terrain are needed to accurately predict overland flow. Therefore the acquisition of high resolution digital elevation data is necessary for accurately mapping overland flow paths (Leitão et al., 2015). Lidar - a technology that measures the distance to a target based upon the travel time of reflected light - is still at the forefront of high-resolution 3D data collection methods (Hodgetts, 2013). Novel methods for photo based 3D surface reconstruction, however, have opened a new pathway for developing solutions to affordably and efficiently generate very high resolution digital terrain models. Photogrammetric techniques have long been used to derive topographic data from analogue imagery such as stereo aerial photographs. Recent advances in computer vision computer algorithms coupled with the availability and affordability of digital cameras, however, have lead to dramatic improvements in the collection and processing of terrain data using photogrammetry. The novel photogrammetric approach called Structure-from-Motion (SfM) enables fully automatic generation of high resolution digital terrain models using multi-view stereo techniques to derive 3D data from imagery taken with consumer grade cameras. This approach can be used to examine objects captured with terrestrial photographs as well as aerial imagery (Bemis et al., 2014). The rising number of applications and innovations is driven by the increasing accessibility of Unmanned Aerial Systems (UAS) technology. Until recently, most UAS applications were military. In the last decade, however, the emerging market for small (sUAS), light and easy to use systems led to UAS applications in industry, research and entertainment. Geoscientists have taken advantage of the integration of sUAS and the SfM approach; numerous geoscience studies have demonstrated the relevance, cost-effectiveness and effi-

\footnotetext{
${ }^{*}$ Corresponding author
}

ciency of this approach. Procedures for obtaining imagery using unmanned platforms and processing acquired data in photogrammetric software no longer require expert knowledge and experience. The high degree of automation in photogrammetric flight planning and execution and the availability of numerous software packages utilizing SfM algorithms make the extraction of threedimensional coordinates from sufficiently overlapping photography possible (Tonkin et al., 2014) even without camera location and orientation data (Snavely et al., 2008; Westoby et al., 2012). It has been demonstrated that this approach produces terrain models with resolution and data quality equivalent to or better than lidar (Carrivick et al., 2013; Fonstad et al., 2013). Legal procedures, however, currently limit UAS data collection as regulations are still being adapted to this new, rapidly growing field (Summary of North Carolina Regulations concerning Unmanned Aircraft Systems, 2015).

It is clear that the photographs cannot replace lidar's capability of obtaining the bare ground surface by filtering the vegetation cover. On the other hand the high cost of laser scanning surveys makes the acquisition of time series expensive. Cost may limit temporal resolution, a disadvantage when a study area undergoes frequent or sudden terrain changes. Arable land, for example, is subject to seasonal changes, crop rotation, and soil redistribution by intense tillage (Su et al., 2012; Ferreira et al., 2015). Furthermore, arable land is susceptible to intensive erosion, which can modify its terrain and cause the formation of gullies (Ferreira et al., 2015).

Several studies have investigated the impact of digital elevation model (DEM) resolution on change detection (Wheaton et al., 2010 (Wheaton et al., 2010; Brasington et al., 2012) and flow modeling results (Fewtrell et al., 2011; Leitão et al., 2015). Leitão et al. (2015) demonstrated that high resolution terrain models generated with SfM techniques from aerial photographs produce satisfactory results for urban overland flow modeling. This phenomenon is of particular significance for agricultural land. A study by Hyväluoma et al. (2013) demonstrated that tillage can 
significantly modify overland flow in cultivated areas, but also highlighted the DEM limitations in representing the flow pattern.

In this paper we propose a robust approach for analyzing microtopography controls on surface water flow, drainage and ponding in agricultural landscape based on sUAS derived high-resolution elevation models. The objectives of this paper:

- to assess the suitability of digital surface models (DSMs) produced by sUAS photogrammetry for overland flow simulation in the context of precision agriculture applications,

- to develop a workflow for overland flow pattern simulation using high spatial and temporal resolution DSMs derived from sUAS data, and

- to investigate the differences between flow patterns based on sUAS derived DSMs and lidar based DEMs.

The rest of the paper is organized as follows: first we introduce the data acquisition techniques and materials and we characterize the study area features. The next section is dedicated to methodology of geoprocessing sUAS derived data and description of the algorithm used for overland flow modeling. After presenting results of the research we summarize them in the last section that contains conclusions, discusses possible issues and suggests issues that are worth further investigation.

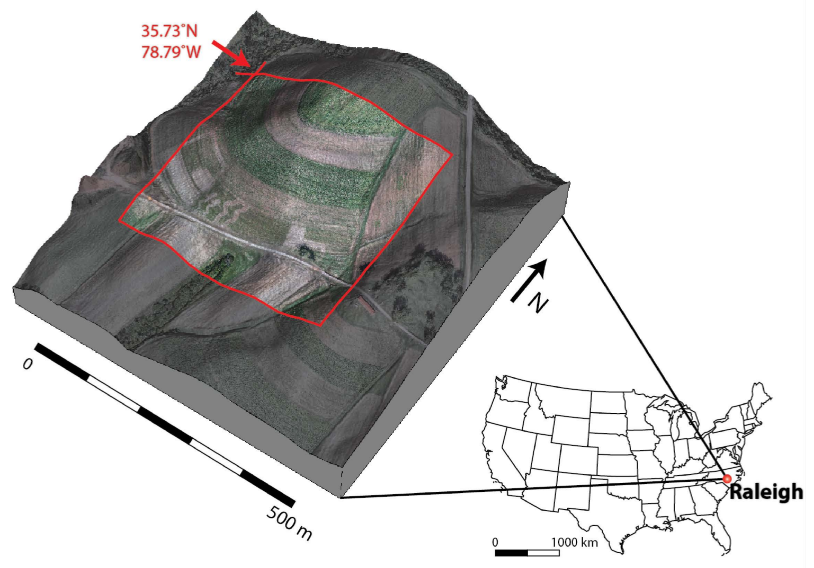

Figure 1: The targeted area, Lake Wheeler Road Field Laboratory of North Carolina State University, Raleigh, NC

\section{STUDY AREA}

The study area (Figure 1) is located within the jurisdiction of the City of Raleigh and Wake County, in the central region of North Carolina, USA at the Lake Wheeler Road Field Laboratory of North Carolina State University (NCSU). Although located within the city limits, the farm is a part of delimited Special Area that has been identified by the local authorities as protection area for maintaining water quality in the Swift Creek Watershed (The 2030 Comprehensive Plan for the City of Raleigh, 2002). Current policy limits future development within the area. The majority of this protected area is now used for agricultural research.

Legal regulations regarding sUAS flights in North Carolina limit sUAS activity (Summary of North Carolina Regulations concerning Unmanned Aircraft Systems, 2015). The farm is located in one of the six areas in North Carolina for which NextGen Air
Transportation Group (NGAT) was granted the Certificates of Waiver or Authorization (COA). This authorization issued by the Air Traffic Organization to a public operator allows the holder specific legal UA activity within its borders.

The 11.82 ha area $\left(35^{\circ} 43^{\prime} 44^{\prime \prime} \mathrm{N}, 78^{\circ} 41^{\prime} 54^{\prime \prime} \mathrm{W}\right)$ was selected based on the terrain features, changing land cover and presence of stable features such as roads. The elevation within the area varies from 105 to $120 \mathrm{~m}$ a.s.l. Most of this area is arable land maintained by the Lake Wheeler Road Field Lab of North Carolina State University. Soils within the area range from fine sandy loam to sandy loam and are classified are eroded due to intensive agricultural exploitation (City of Raleigh iMap portal, 2015).

\section{DATA ACQUISITION}

The time series of elevation data used for the analysis of surface water flow patterns was derived from imagery collected by repeated sUAS surveys of the study area over the time period of eight months. Airborne lidar data acquired for a 2013 Wake county survey were used to generate the reference DEM and DSM.

\subsection{Unmanned Aerial System}

The Unmanned Aerial System used in this study is UX5 produced by Trimble. This system consists of a fixed wing aircraft and a designated tablet controller. The manufacturer provides a software for flight planning and control - Trimble Access Aerial Imaging application. This allows for an automated workflow and semi-autonomous flight. The airframe wingspan of $1 \mathrm{~m}$ and the weight of only $2.5 \mathrm{~kg}$ make the system suitable for a rapid deployment, thus it can be used for monitoring post-storm landscape response. It cannot be used for observation during a storm, because the system is not able to operate in heavy rain and winds exceeding $65 \mathrm{~km} / \mathrm{h}$ (Trimble, 2015). The onboard sensor is a consumer grade camera Sony NEX-5T capturing RGB imagery. In order to achieve the desired imagery resolution of about $3 \mathrm{~cm}$, the flight ceiling during the executed flights was set to about $100 \mathrm{~m}$ (Table 1). The $14.8 \mathrm{~V}, 6000 \mathrm{mAh}$ battery allows for 50 minute flight that can cover up to $19 \mathrm{~km}^{2}$ in one mission (Trimble, 2015). The flight mission can be prepared beforehand, with the full control of the desired quality of output products and the flight path.

\subsection{Flight missions}

The data were collected during five flights (Table 1) executed by NGAT in 2015 between the months of March and October to capture the changes in the fields during the growing season. There is a 225 days timespan between the first and last flight. All flights were executed after several days of significant rainfall except for the flight on September 21st flown after a dry period (Figure 2). In order to ensure the accuracy of the final results, multiple Ground Control Points (GCPs) were set in the field and the overlap of the photos was set to $80 \%$ in all the flights. Depending on the visibility, 6 to 11 GCPs were identified during data processing.

\subsection{Lidar data}

Due to the rapid development of the Raleigh metropolitan area and the need of sustainable land management, high resolution elevation data were recently acquired to support conservation planning, design, research, floodplain mapping, and hydrologic modeling. This airborne lidar survey was the result of a project combining varied interests of Wake County, City of Raleigh and Town of Cary resulting in detailed multiple return and ground elevation data covering approximately $2500 \mathrm{~km}^{2}$. The acquisition was 


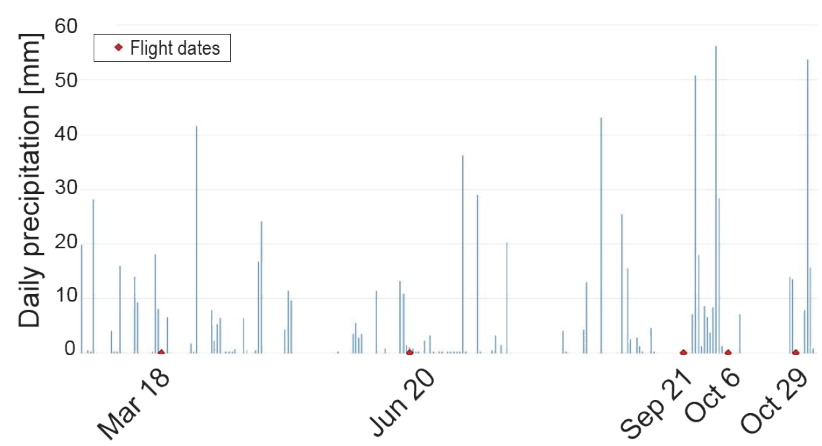

Figure 2: Flight dates and daily precipitation between Mar 1, 2015 and Oct 31, 2015 for Lake Wheeler Rd. Field Lab Station

\begin{tabular}{lrrrrr}
\hline date & $\begin{array}{r}\text { resolution } \\
{[\mathrm{cm} / \mathrm{px}]}\end{array}$ & GCPs & $\begin{array}{r}\text { error } \\
{[\mathrm{px}]}\end{array}$ & $\begin{array}{r}\text { density } \\
{\left[\mathrm{pts} / \mathrm{m}^{2}\right]}\end{array}$ & $\begin{array}{r}\text { altitude } \\
{[\mathrm{m}]}\end{array}$ \\
\hline Mar 18 & 3.11 & 6 & 0.047 & 64.73 & 88 \\
Jun 20 & 3.31 & 11 & 0.080 & 63.75 & 100 \\
Sep 21 & 3.12 & 6 & 0.091 & 63.88 & 100 \\
Oct 06 & 3.12 & 9 & 0.125 & 63.80 & 100 \\
Oct 29 & 3.18 & 9 & 0.135 & 61.63 & 100 \\
\hline
\end{tabular}

Table 1: Properties of sUAS surveys performed in the year 2015: date, ground resolution of the photos, number of GCPs, GCPs error, point densities and flight altitude. All surveys were flown after significant rainfall period, except for Sep 21.

completed in February 2013 using ALS70 HP at 2750 m a.g.l., $40^{\circ}$ field of view, $11 \%$ minimum sidelap, $0.82 \mathrm{~m}$ average point spacing. All deliverables met or exceeded standards for both vertical and horizontal accuracy of $95 \%$ confidence for $0.623 \mathrm{~m} \mathrm{(2}$ $\mathrm{ft}$ ) contours, according to NDEP Guidelines for Digital Elevation Data (NDEP, 2004). The classified point cloud from this survey was used to generate reference DEM and DSM for the study area.

\section{METHODS}

To perform the high resolution surface flow analysis a series of $0.3 \mathrm{~m}$ resolution DSMs was generated from the lidar and sUAS derived point clouds. The DSMs were evaluated for accuracy and geometric distortions using the GCPs and lidar based DSM. Overland flow was then simulated for a given design storm using path sampling method for solution of bivariate shallow water flow equations. The processing of sUAS imagery was performed in PhotoScan Professional by Agisoft (Agisoft, 2013), computation of DSMs and flow analysis was carried out using GRASS GIS (Neteler et al., 2012).

\subsection{Photogrammetric UAS data processing}

The images acquired by UAS were processed using structure from motion (SfM) to derive orthophotography and 3D point clouds. This technique - designed for extraction of 3D coordinates from sufficiently overlapping photography adjusted to the needs of UAS data - has been implemented in several photogrammetric software packages. After evaluation of several proprietary and opensource solutions, the software PhotoScan Professional by Agisoft was chosen for UAS data processing in this study. This system provides a semi-automatic, intuitive workflow and supports custom settings in each step of geoprocessing. It is widely used in the research, i.e. (Gonçalves and Henriques, 2015; Leon et al., 2015; Javernick et al., 2014; Uysal et al., 2015), because of its solid performance and relatively efficient processing.
Agisoft PhotoScan is a proprietary package, thus the algorithms utilized during geoprocessing are not fully documented (Gonçalves and Henriques, 2015). The final products of the standard workflow, described by manufacturer (Agisoft, 2013) are an orthomosaic and a Digital Surface Model (DSM).

After the visual inspection of the photographs, the relevant imagery is loaded to the program and the preliminary adjustment is executed using the camera orientation log. Image feature points (geometrical similarities) and their movement throughout the sequence of multiple images is monitored and based on this information feature points are rendered as a 3D sparse point cloud. This procedure can be executed also without the information about the external orientation of a camera that is included in the flight $\log$. The correct values of localization (coordinates, altitude) and orientation (pitch, yaw, roll) parameters of a sensor at the moment of photo capture are determined in the aerial triangulation process, but the processing is faster if approximate values for these parameters are known. This procedure is coupled with camera self-calibration, which resolves the issue of using a nonphotogrammetric camera, although the inaccuracy of these estimates together with the algorithms used by the software cause the deformation known as a doming error (James and Robson, 2014). The issue can be resolved by performing optimization based on ground control data. The GCPs are identified on each photo, where the marker is visible and the optimization is carried out based on the known, pre-measured and accurate positions of the ground points.

The construction of dense point cloud is performed by calculating depth maps for every image. PhotoScan determines the quality of the generated point cloud, but the more accurate the camera position estimates are, the more time and memory intensive the process will be. For our study the medium quality setting was chosen based on the memory required for the number of photos included in the processing. Efficient processing was possible only in a special height-field mode available in PhotoScan, which is highly optimized for aerial imagery (Agisoft, 2013).

Further steps recommended by the manufacturer - meshing and texture generation - are necessary for generating DSMs and orthophotos in the software. We, however, decided to export the raw, georeferenced point cloud from PhotoScan and generate all DSMs with the same technique as the lidar based point cloud in order to compare the results of overland flow simulations based on data acquired by lidar and UAS. The orthophoto, produced with default values in PhotoScan was used for the validation purposes.

\subsection{Classification and interpolation of point clouds}

In order to model and compare water flow on raster DSMs from two completely different sources of elevation data - lidar and sUAS SfM - we derived all the DSMs from raw points clouds using the same technique, giving us control over the desired resolution and level of detail captured in the resulting DSMs. The process consists of removing tree crowns from the point clouds and interpolating the DSMs using regularized spline with tension (Mitasova et al., 2005).

The sUAS based point clouds captured several large trees in the south-east part of our study area. The tree crowns were represented as clusters of points with many outliers, often with points below the ground indicating the high uncertainty and large errors associated the reconstructed trees. To minimize the impact of the tree crowns represented in the raster on water flow modeling, we classified high vegetation and removed it from the point clouds using a modified multiscale curvature classification method (Evans 


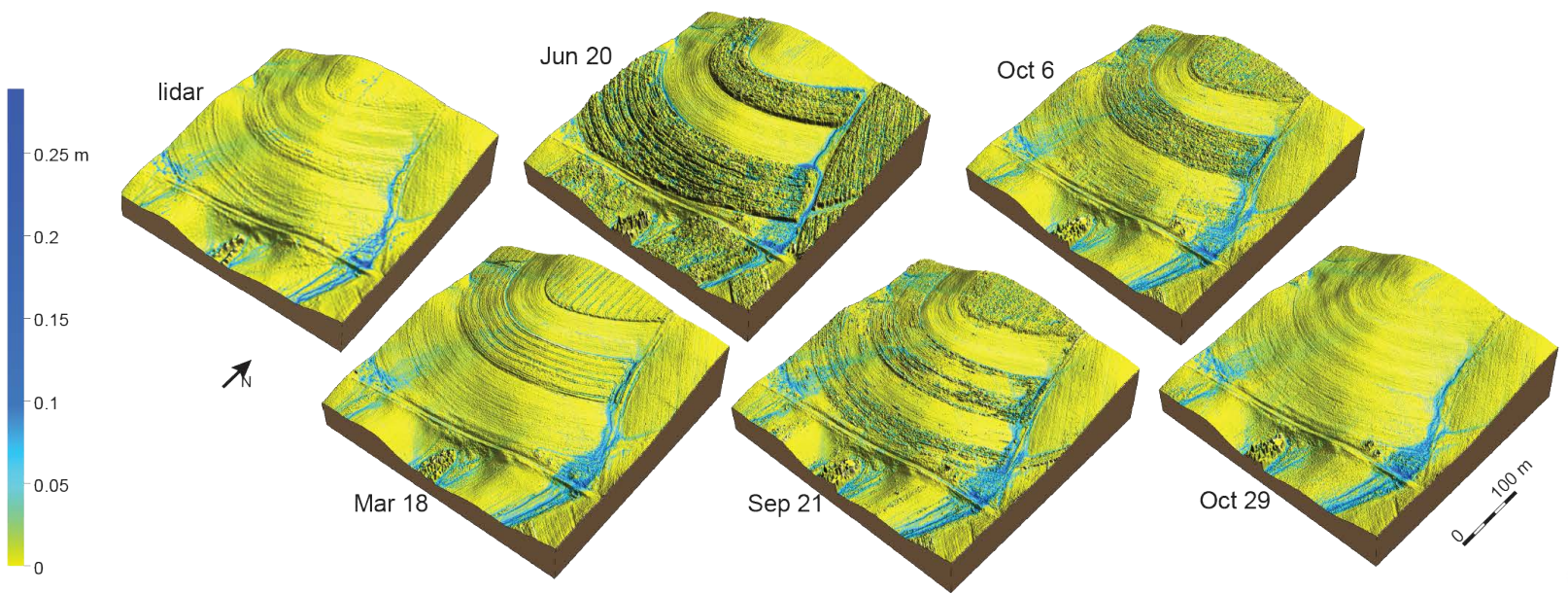

Figure 3: Overland flow pattern simulated for the lidar based DEM and DSMs based on the sUAS derived data in 5 flights in 2015
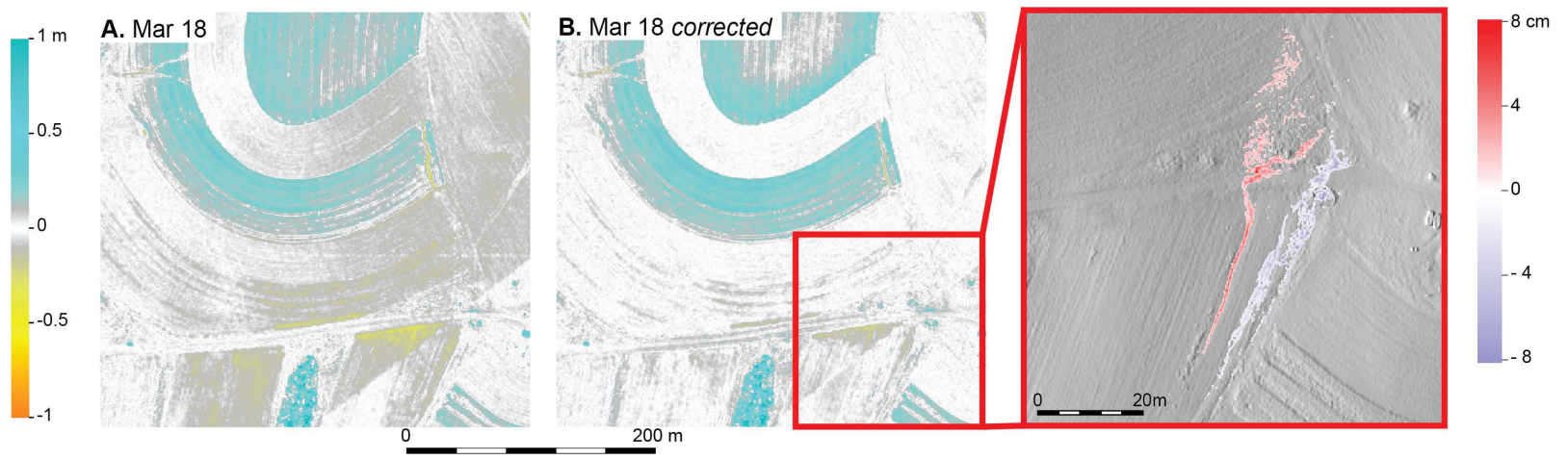

Figure 4: Differences in elevation between the lidar and sUAS based terrain models from the March flight. Figure A shows in blue areas where sUAS based DSM is higher than lidar. In B we show the difference after applying the shift correction and the inset shows the differences higher than $1 \mathrm{~cm}$ of overland flow depth simulated on these two DSMs.

and Hudak, 2007) implemented in v.lidar.mcc tool (Blumentrath, 2014) available in GRASS GIS. Although originally designed for lidar data, this method is suitable for sUAS based point clouds because it doesn't require point return type. We successfully identified and filtered high vegetation from the point clouds, however, not surprisingly, it was not possible to distinguish low vegetation such as crops and bushes due to their high density and small number of ground points. Lidar data were already classified by the vendor and therefore we used bare ground class for further processing. We derived all sUAS based DSMs and lidar bare earth surface at $0.3 \mathrm{~m}$ resolution. Since we want to compare the flow patterns at the same resolution, we chose this resolution as it is still suitable for sparser lidar data and at the same time we do not loose too much detail of the dense sUAS data. The lidar data were interpolated using regularized spline with tension implemented in GRASS GIS as v.surf.rst module (Mitasova et al., 2005). We used a relatively low tension value of 20 and with smoothing value set to 1 to suppress the pattern of the scan lines while preserving the tillage surface geometry. The sUAS data were then processed in the same way.

To assess the possible influence of spatial distortion of the SfM reconstruction on water flow patterns, we analyzed the differences between sUAS DSMs and lidar data. For each DSM, we computed a corrected DSM by extracting a trend surface from the difference to lidar and subtracted it from the original DSM. We derived the trend surface by computing median of the difference using moving window with large size $(100 \mathrm{~m})$. Prior to that we removed areas of difference higher than $10 \mathrm{~cm}$ to not influence the trend by vegetation. The original and the corrected DSM were then compared in regard to water flow patterns, to see whether DSMs' distortions of such magnitude matter for water flow pattern.

\subsection{Overland flow simulation}

Flow modeling at sub-meter resolutions is challenging due to high complexity of the terrain surface, including extensive nested real depressions. Surface flow modeling methods that rely on a depressionless DEM require substantial modification of this type of high resolution DEM, limiting the capability to capture the impacts of microtopography on the flow pattern or on ponding in the depressions. The path sampling technique, also referred to as Green's function Monte Carlo, has been proposed as a robust, mesh-free alternative for solving the shallow water flow continuity equation on complex surfaces (Mitasova et al., 2004). The technique is based on duality between the particle and field representation: in this concept, the density of particles in space defines a field and vice versa, a continuous field is represented by particles (path samples) with corresponding spatial distribution. Using this duality, processes can be modeled as evolution of fields or evolution of spatially distributed particles.

To capture the spatial and temporal variability of surface water flow over tilled agricultural fields and across unpaved service roads, we solve the following bivariate continuity equation (see 
more details in Mitasova et al. (2004)):

$$
-\frac{\varepsilon}{2} \nabla^{2} h^{5 / 3}+\nabla \cdot(h \mathbf{v})=i_{e}
$$

where $h$ is the depth of overland flow [m], $\mathbf{v}$ is flow velocity vector $\mathbf{v}=\left(v_{x}, v_{y}\right)[\mathrm{m} / \mathrm{s}], i_{e}$ is rainfall excess (rainfall - infiltration - vegetation intercept) $[\mathrm{m} / \mathrm{s}]$, and $\varepsilon$ is a spatially variable diffusion coefficient. The diffusion term, which depends on $h^{5 / 3}$ instead of $h$, makes the Equation (1) linear in the function $h^{5 / 3}$ which enables us to solve it by the Green's function path sampling method. The solution is then described as a function with statistical error proportional to $1 / \sqrt{M}$ where $M$ is the number of walkers. Incorporation of the spatially variable diffusion term $\varepsilon$ supports approximate simulation of water depth evolution in locations with flat topography and depressions. By defining the diffusion term as a function of water depth and the velocity of flow as a function of an approximate water flow momentum, water fills the depressions and flows out in the prevailing flow direction. The method was implemented in GRASS GIS in the module r.sim.water.

We used path sampling to simulate shallow overland water flow and ponding in depressions for a design storm, assuming uniform rainfall excess rate of $30 \mathrm{~mm} / \mathrm{hr}$ and a uniform surface roughness coefficient 0.15. For each DSM in the time series we ran the simulation at $0.3 \mathrm{~m}$ resolution for 40 minutes until steady state was reached in most of the modeled area.

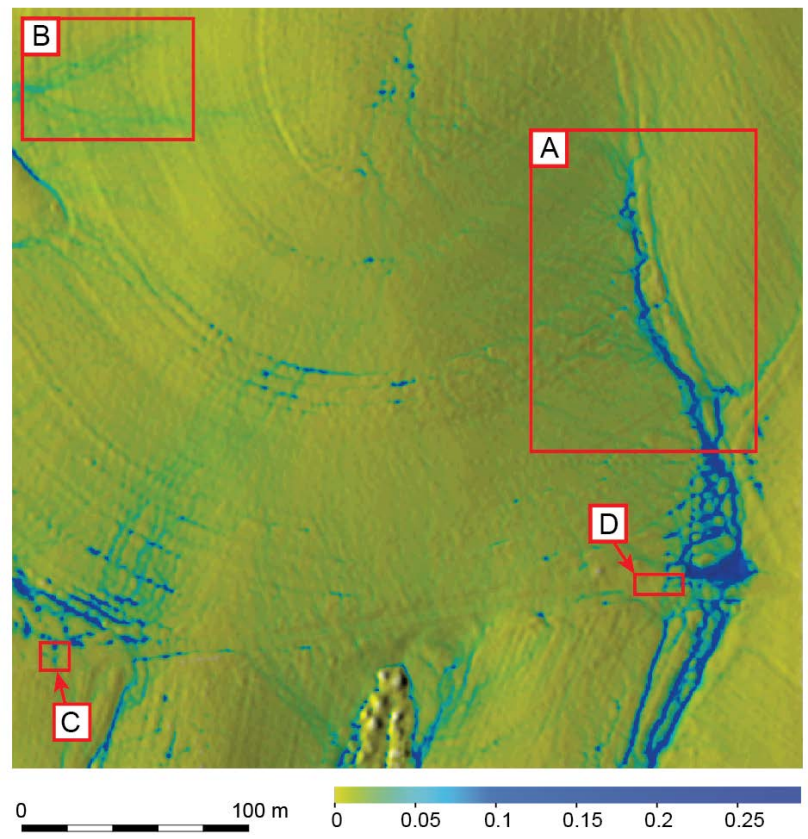

Figure 5: Areas of a special importance, enlarged on figures 6, 7, 8 , and 9

\section{RESULTS AND DISCUSSION}

In this section we present the results of the overland flow simulation based on sUAS and lidar derived data. We focus on the differences in the generated terrain models that are the source of the discrepancies between final simulations. We analyze the generated overland flow patterns and validate them based on the orthophotos depicting actual conditions of terrain during sUAS data acquisition.

\subsection{Assessment of DSM time series accuracy and spatial pat- tern of distortions}

The assessment of the 2013 lidar DEM accuracy based on the 12 available GCPs (installed in 2015) confirmed its high accuracy with mean difference of $5 \mathrm{~cm}$ and RMSE of $8.7 \mathrm{~cm}$.
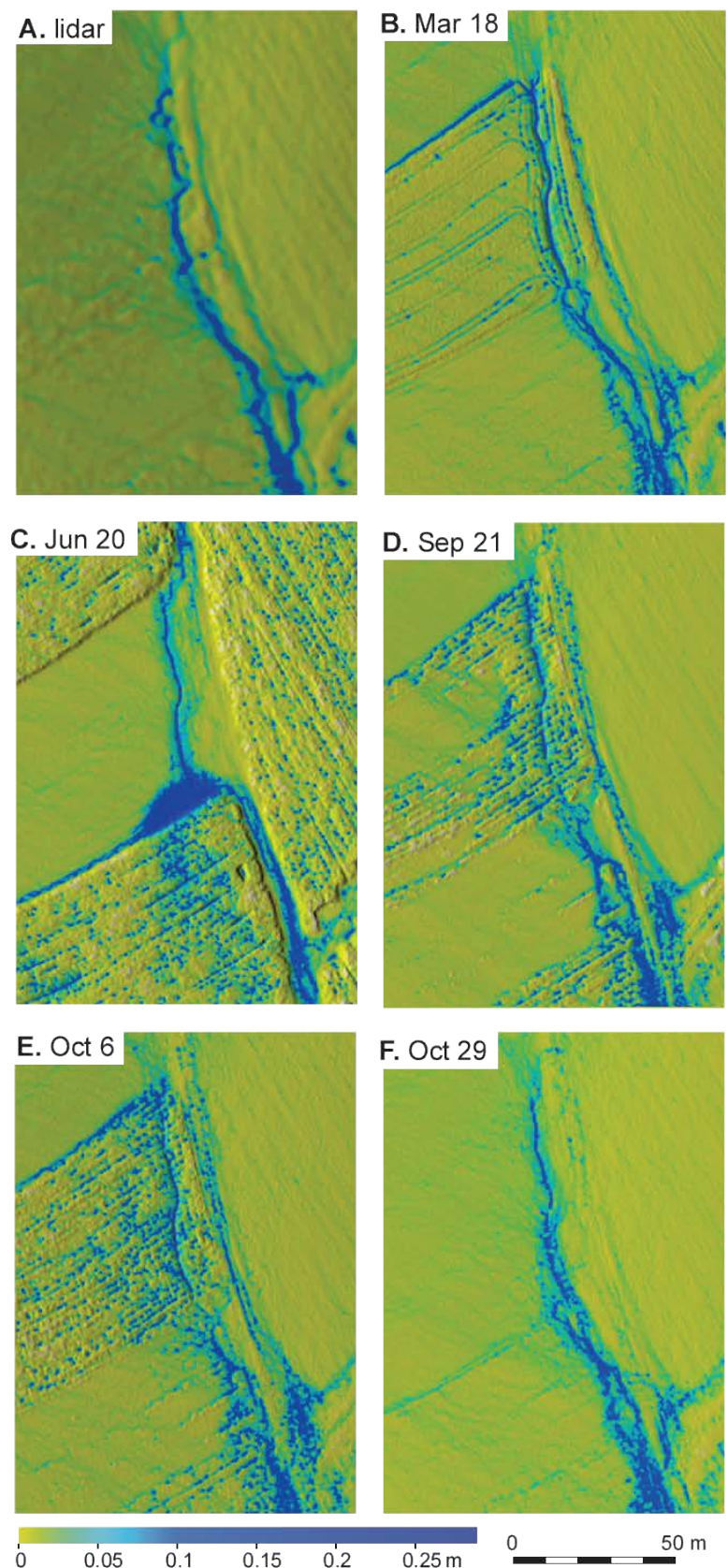

Figure 6: Enlarged area A from Figure 5, with the visible gully

The mean differences between DSMs derived from aUAS surveys ranged from $-0.1 \mathrm{~cm}$ in March to $36.6 \mathrm{~cm}$ in June (Table 2) and RMSE ranges from $1.3 \mathrm{~cm}$ in March to $39.2 \mathrm{~cm}$ in June and the spatial distribution of differences varies between the flights. The differences between the example SUAS derived DSM from March and lidar based DEM is shown in Figure 4.

To examine the impact of spatial distortions of the SfM reconstruction on flow pattern, we computed water flow on the original DSMs and on the DSMs corrected using the method described in 

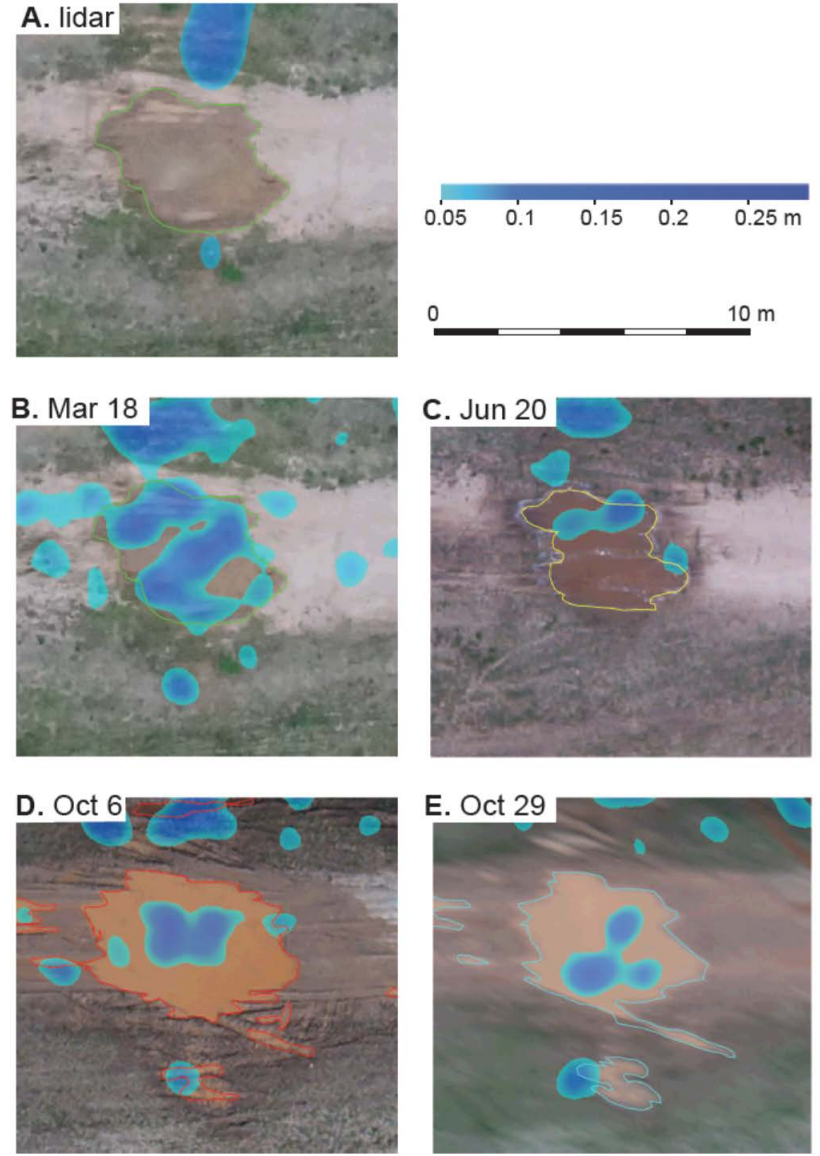

Figure 7: The puddle on the service road (enlarged area $\mathrm{C}$ from Figure 5) captured on the orthophoto from Mar 18 (A and B), Jun 20 (C), Oct 06 (D) and Oct 29 (E) with displayed results of overland flow simulations on lidar based DEM (A) and DSMs based on sUAS data collected Mar 18 (B), Jun 20 (C), Oct 06 (D) and Oct 29 (E)

Section 4.2. The comparison of the result on March DSM shows that spatial distortions of such magnitude can slightly alter the distribution of water on the landscape. They do not, however, significantly affect the patterns of water flow. Based on these finding we show here the water flow simulation results computed on the original DSMs.

The DSMs were generated using the same parameters (see the methods) but the accuracy of the results varied (Table 1) based on the flight conditions and availability of GCPs. The second flight in October produced relatively low quality images due to windy conditions and trouble placing GCPs.

Comparison of DSMs with lidar based DEM revealed spatially variable pattern of geometric distortions (Figure 4). As predicted,

\begin{tabular}{lrr}
\hline date & RMSE & mean \\
\hline Mar 18 & 11.5 & -0.1 \\
Jun 20 & 62.6 & -36.7 \\
Sep 21 & 20.0 & 8.3 \\
Oct 06 & 15.7 & 1.6 \\
Oct 29 & 19.3 & 13.9 \\
\hline
\end{tabular}

Table 2: Comparison of lidar based DSM and sUAS derived DSMs, RMSE - root-mean-square error [cm], mean - mean difference between lidar DSM and sUAS DSM [cm],
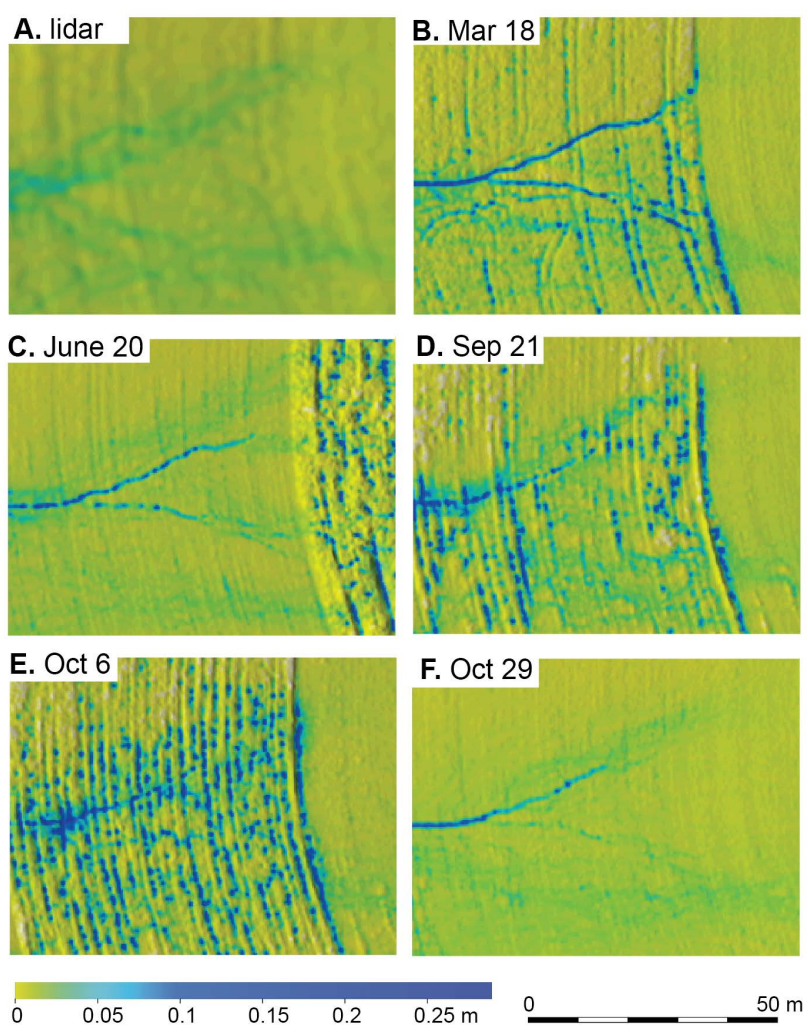

Figure 8: Enlarged area B from Figure 5, with the visible gully

the presence of the mature corn plants made it impossible to capture the bare ground with the sUAS camera and resulted in creating an artificial surface at the height of the plants. The DSM based on the June data shows the greatest differences compared to the lidar DEM with the mean of absolute values of differences as high as (see Figure 4 and Table 1) $-36.7 \mathrm{~cm}$. This will significantly influence the simulated flow pattern described below. The other area with substantial differences is located at the foothill and therefore does not influence the flow pattern.

\subsection{Evolution of the overland flow pattern}

The results of the overland flow simulation show a persistent, relatively stable flow pattern in spite of changes in the field due to tillage, crop growth and harvest (Figure 3). Small gullies were observed in the fields (Figure 5 A, B) and water ponded in depressions on the service roads (Figure $5 \mathrm{C}, \mathrm{D}$ ). sUAS data captured the redirection of flow and accumulation of water caused by tillage with greater detail than the lidar data. It is clearly visible in the areas not covered by vegetation. The growing crops significantly disturb the flow pattern, creating an artificial ponding effect caused by representing the height of the corn as the elevation surface.

We observed two small gullies in the study area. Over the 9 months covered by our UAS surveys the location, shape and extent of these gullies did not change significantly in spite of several storms and crop rotation. The gully A depicted in Figure 6 is visible on lidar and sUAS data. It shows consistent pattern through the seasons, with the exception of the June DSM, where the dense vegetation being part of the terrain creates an artificial ponding pattern. The smaller plants are not occluding the ground surface and their influence on the flow pattern is negligible. The second gully in the NW corner of the study area is not clearly visible on the lidar data (Figure 8). It is captured on all the sUAS DSMs, 

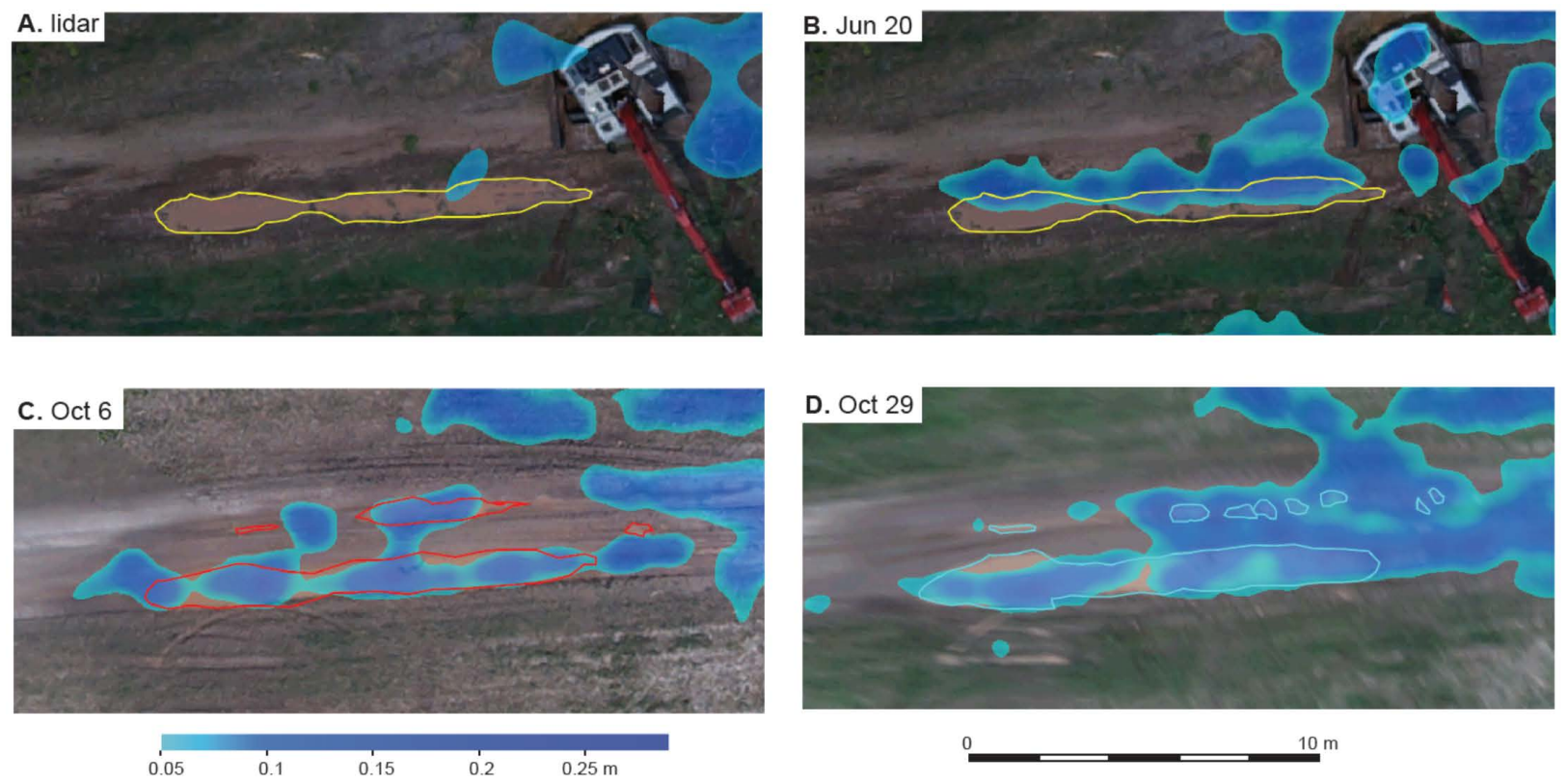

Figure 9: The puddle along the service road (enlarged area D from Figure 5) captured on the orthophoto from Jun 20 (A and B), Oct 06 (C) and Oct 29 (D) with displayed results of overland flow simulations based on lidar based DSM (A) and sUAS data collected Jun 20 (B), Oct 06 (C) and Oct 29 (D).

however during September and October the gully is disrupted by the presence of vegetation resulting in less clear but still recognizable shape. There are two explanations for the absence of the gully in the lidar data. Since the lidar survey was conducted two years before capturing the sUAS imagery, the gully could have developed after the lidar data collection. It is also possible that due to the lower detail of lidar based data the micro changes in the terrain are not well represented (similar to the tillage pattern) and the simulation reflects this simplified micro relief. While lidar data can be helpful for identifying areas vulnerable to erosion, sUAS based data is needed to identify and monitor gully formation.

\subsection{Prediction and validation of water ponding on service roads}

As there has not been any direct monitoring of runoff during storms, we validated the prediction of water flow patterns by comparing ponding on service roads predicted in the simulation with the actual situation in the field known from the orthophotos generated as part of the SfM reconstruction. In the orthophotos from June and both October missions several puddles appear along the unpaved road in the southern part of the targeted area (Figure 5 C, D). Despite the fact that puddles of turbid water are interpreted as ground surface by the SfM algorithm and thus we cannot accurately represent the local depressions, we hypothesized that the sUAS derived data still provide more accurate representation of the overland flow pattern than lidar data. Simulation based on the lidar $\mathrm{DEM}^{1}$ (Figure 9, A) does not predict the water accumulation along the road (Figure $5 \mathrm{D}$ ), while the shape of the puddle aligns with the sUAS based simulations in all cases (Figure 9, B, C, D). This is also confirmed for the smaller puddle (Figure $5 \mathrm{C}$ ), where the water is visible additionally after the March rainfall (Figure 7). Our results show that sUAS derived data allow for accurate spatial prediction of surface water on service roads which provides valuable information for road maintenance and assessment of accessibility after storms. It can improve delineation of the potentially inundated areas and thus enables

\footnotetext{
${ }^{1}$ There was no orthophoto available for the time of lidar data survey.
}

landowners to adjust water management practices and prevention procedures.

\section{CONCLUSIONS}

Agricultural areas are characterized by frequent changes in microtopography that influence the surface water flow. It is therefore crucial to obtain the most recent and detailed representation of terrain surface for overland flow modeling. This study investigated the possibility of using high spatial and temporal resolution data acquired by small Unmanned Aerial System for mapping flow paths. The results have been compared with the simulations based on the lidar derived DEM and the following conclusions have been drawn:

- sUAS derived data can improve the quality of the flow pattern modeling due to the increased spatial and temporal resolution. It can capture preferential flow along tillage that is represented by capturing the changing microtopography.

- Overland water flow modeling based on data from airborne lidar surveys is suitable for identifying potentially vulnerable areas. sUAS based data, however, is needed to actually identify and monitor gully formation.

- Due to the high resolution of obtained data, vegetation significantly disrupts the flow pattern. Therefore densely vegetated areas are not suitable for water flow modeling.

Future work will concentrate on eliminating the artificial ponding effect by replacing parts of the sUAS derived data covered with dense vegetation with the bare earth lidar point cloud. These simulations extended by new data from future flight will be used for designing a validation experiment.

\section{References}

The 2030 Comprehensive Plan for the City of Raleigh, 2002. 
Agisoft, 2013. Agisoft PhotoScan User Manual: Professional Edition. Version 1.0.0 edn.

Bemis, S. P., Micklethwaite, S., Turner, D., James, M. R., Akciz, S., Thiele, S. T. and Bangash, H. A., 2014. Groundbased and uav-based photogrammetry: A multi-scale, highresolution mapping tool for structural geology and paleoseismology. Journal of Structural Geology 69, Part A, pp. 163 178

Bevington, J., Piragnolo, D., Teatini, P., Vellidis, G. and Morari, F., 2016. On the spatial variability of soil hydraulic properties in a holocene coastal farmland. Geoderma 262, pp. $294-305$.

Blumentrath, S., 2014. v.lidar.mcc GRASS GIS module.

Brasington, J., Vericat, D. and Rychkov, I., 2012. Modeling river bed morphology, roughness, and surface sedimentology using high resolution terrestrial laser scanning. Water Resources Research 48(11), pp. n/a-n/a. W11519.

Carrivick, J. L., Smith, M. W., Quincey, D. J. and Carver, S. J., 2013. Developments in budget remote sensing for the geosciences. Geology Today 29(4), pp. 138-143.

City of Raleigh iMap portal, 2015. Environmental layers group; Soils layer.

Evans, J. S. and Hudak, A. T., 2007. A multiscale curvature algorithm for classifying discrete return LiDAR in forested environments. IEEE Transactions on Geoscience and Remote Sensing 45(4), pp. 1029-1038.

Ferreira, V., Panagopoulos, T., Cakula, A., Andrade, R. and Arvela, A., 2015. Predicting soil erosion after land use changes for irrigating agriculture in a large reservoir of southern portugal. Agriculture and Agricultural Science Procedia 4, pp. 40 - 49. Efficient irrigation management and its effects in urban and rural landscapes.

Fewtrell, T. J., Duncan, A., Sampson, C. C., Neal, J. C. and Bates, P. D., 2011. Benchmarking urban flood models of varying complexity and scale using high resolution terrestrial lidar data. Physics and Chemistry of the Earth, Parts A/B/C 36(78), pp. 281 - 291. Recent Advances in Mapping and Modelling Flood Processes in Lowland Areas.

Fonstad, M. A., Dietrich, J. T., Courville, B. C., Jensen, J. L. and Carbonneau, P. E., 2013. Topographic structure from motion: a new development in photogrammetric measurement. Earth Surface Processes and Landforms 38(4), pp. 421-430.

Gonçalves, J. and Henriques, R., 2015. UAV photogrammetry for topographic monitoring of coastal areas. ISPRS Journal of Photogrammetry and Remote Sensing 104, pp. $101-111$.

Hodgetts, D., 2013. Laser scanning and digital outcrop geology in the petroleum industry: A review. Marine and Petroleum Geology 46, pp. 335 - 354.

Hyväluoma, J., Lilja, H. and Turtola, E., 2013. An anisotropic flow-routing algorithm for digital elevation models. Computers and Geosciences 60, pp. $81-87$.

James, M. R. and Robson, S., 2014. Mitigating systematic error in topographic models derived from UAV and ground-based image networks. Earth Surface Processes and Landforms 39(10), pp. 1413-1420.
Javernick, L., Brasington, J. and Caruso, B., 2014. Modeling the topography of shallow braided rivers using structure-frommotion photogrammetry. Geomorphology 213, pp. $166-182$.

Leitão, J. P., Moy de Vitry, M., Scheidegger, A. and Rieckermann, J., 2015. Assessing the quality of digital elevation models obtained from mini-unmanned aerial vehicles for overland flow modelling in urban areas. Hydrology and Earth System Sciences Discussions 12(6), pp. 5629-5670.

Leon, J., Roelfsema, C. M., Saunders, M. I. and Phinn, S. R., 2015. Measuring coral reef terrain roughness using Structurefrom-Motion close-range photogrammetry. Geomorphology 242 , pp. $21-28$. Geomorphology in the Geocomputing Landscape: GIS, DEMs, Spatial Analysis and statistics.

Mitasova, H., Mitas, L. and Harmon, R., 2005. Simultaneous spline approximation and topographic analysis for lidar elevation data in open-source GIS. IEEE Geoscience and Remote Sensing Letters 2, pp. 375-379.

Mitasova, H., Thaxton, C., Hofierka, J., McLaughlin, R., Moore, A. and Mitas, L., 2004. Path sampling method for modeling overland water flow, sediment transport, and short term terrain evolution in Open Source GIS. Developments in Water Science 55, pp. 1479-1490.

NDEP, 2004. Guidelines for digital elevation data.

Neteler, M., Bowman, M., Landa, M. and Metz, M., 2012. GRASS GIS: a multi-purpose Open Source GIS. Environmental Modelling \& Software 31, pp. 124130.

Snavely, N., Seitz, S. and Szeliski, R., 2008. Modeling the world from internet photo collections. International Journal of Computer Vision 80(2), pp. 189-210.

Su, Z., Zhang, J., Qin, F. and Nie, X., 2012. Landform change due to soil redistribution by intense tillage based on high-resolution DEMs. Geomorphology 175176, pp. 190 - 198.

Summary of North Carolina Regulations concerning Unmanned Aircraft Systems, 2015.

Tonkin, T., Midgley, N., Graham, D. and Labadz, J., 2014. The potential of small unmanned aircraft systems and structurefrom-motion for topographic surveys: A test of emerging integrated approaches at cwm idwal, north wales. Geomorphology 226 , pp. $35-43$.

Trimble, 2015. Trimble UX5 Unmanned Aircraft System. Datasheet.

Uysal, M., Toprak, A. and Polat, N., 2015. DEM generation with UAV photogrammetry and accuracy analysis in sahitler hill. Measurement 73, pp. $539-543$.

Westoby, M., Brasington, J., Glasser, N., Hambrey, M. and Reynolds, J., 2012. Structure-from-Motion photogrammetry: A low-cost, effective tool for geoscience applications. Geomorphology 179, pp. $300-314$.

Wheaton, J. M., Brasington, J., Darby, S. E. and Sear, D. A., 2010. Accounting for uncertainty in dems from repeat topographic surveys: improved sediment budgets. Earth Surface Processes and Landforms 35(2), pp. 136-156. 